\title{
Molecular Genetics of Addiction Vulnerability
}

\author{
George R. Uhl \\ Molecular Neurobiology Branch, National Institute on Drug Abuse-Intramural Research Program, National Institutes of Health, \\ Box 5180, Baltimore, Maryland
}

\begin{abstract}
Summary: Classical genetic studies document strong complex genetic contributions to abuse of multiple addictive substances, to mnemonic processes that are likely to include those involved in substance dependence, and to the volumes of brain gray matter in regions that are likely to contribute to mnemonic/ cognitive and to addictive processes. The working idea that these three heritable phenotypes are likely to share some of the same complex genetic underpinnings is presented. This review contains association-based molecular genetic studies of addiction that largely derive from my laboratory and their fit with linkage data from other laboratories. These combined results now identify many of the loci and genes that contain allelic variants that are likely to provide the heritable components of human addiction vulnerability. These data are also likely to have broad implications for neurotherapeutics. Drugs with po-
\end{abstract}

tential abuse liabilities are widely used for indications that include pain, anxiety, sleep, seizure, and attentional disorders. There is increasing nonmedical use of these prescribed substances. Increasing information about addiction vulnerability gene variants should help to improve management of risks of dependence in individuals who receive such therapeutics. In addition, since mnemonic components that correlate well with individual differences in brain regional volumes are likely to play major roles in addiction processes, many addiction vulnerability genes are also good candidates to contribute to individual differences in mnemonic processes. Recently elucidation of addiction-associated haplotypes for the "cell adhesion" $\mathrm{Nr}$ CAM gene illustrate several of these points. Key Words: Association genome scanning, linkage, substance dependence, haplotypes, cell adhesion molecules, memory.

\section{INTRODUCTION}

Substance abuse is a complex problem with the concept of "addiction" at its core. Thoughtful dissection and discussion of addictions have long recognized that addicts are not only those who currently abuse substances; they also include many individuals whose prior substance abuse has left them with "drug memories" that manifest in drug cravings, an increased risk of drug self-administration, and other behaviors. Seen from this perspective, mnemonic processes are thus at the core of addictions in both detoxified and currently abusing individuals. ${ }^{1-3}$ Many addictions in the United States occur in individuals who abuse prescribed substances. Drugs prescribed for neurotherapeutic use-not only for pain, but also for ADHD and other attention disorders, sleep disorders, and seizures-may lead to addictions in the individuals for whom the medicines are prescribed, as well as in others to whom the drugs can be diverted. Recent estimates indicate that 72 million Americans report at

Address correspondence and reprint requests to: George R. Uhl, M.D., Ph.D., Box 5180, Baltimore, MD 21224. E-mail: guhl@ intra.nida.nih.gov. least some nonmedical abuse of a prescribed opioid, stimulant, or "tranquilizer."

Family, adoption, and twin studies have contributed knowledge of the genetic contributions to drug abuse vulnerability. Drug abuse vulnerability is familial (reviewed in Uhl et al. ${ }^{5}$ ), and twin data from a number of laboratories strongly support the idea that drug abuse vulnerability has an overall genetic component that explains $40-60 \%$ of the overall vulnerability. ${ }^{6-16}$ Heritable phenotypes include diagnoses of drug dependence and quantity/frequency of drug use. Twin data support the idea that most of the genetic vulnerability to abuse of different legal and illegal addictive substances is shared, although some is substance specific. ${ }^{14,17}$

Substance abuse progresses in most individuals over relatively stereotyped trajectories from experimentation, to use, to regular use, to abuse, to dependence. Many of the phenomena that accompany later stages of progression toward drug dependence appear likely to involve mnemonic and cognitive processes. Twin studies from several laboratories demonstrate that genetics strongly impacts the progression from regular use to dependence (e.g., see Tsuang et al. ${ }^{16}$ ). 
Studies of the ways in which addictions move through families do not support single-gene inheritance. Addictions, like other human disorders that display both genetic and environmental contributions to vulnerability, are thus "complex disorders" that are likely to receive contributions from allelic variations in a number of genes.

Individual differences in performance on memory tests are also substantially heritable in ways that overlap genetically with individual differences in other cognitive abilities. Heritability for working memory is reported to range from 33 to $64 \%$, for example. ${ }^{18}$ Interestingly, the volumes of brain structures important for these mnemonic processes are also substantially heritable. Comparisons of MRI brain images of mono- and dizygotic twin pairs suggest that $\sim 60 \%$ of the individual differences in the volume of frontal lobe regions are heritable, whereas hippocampal volumes display $\sim 40 \%$ heritabilities. ${ }^{19,20}$ Further, these heritable differences in brain volumes account for virtually all of the heritable variance in working memory task performance in at least one large twin study. ${ }^{21}$ Taken together, these lines of evidence support substantial heritable contributions to the structures of brain regions important for mnemonic tasks and performance on memory and cognitive tasks. A working hypothesis that is consistent with current data is that these genetic components are thus likely to share substantial relatedness with the genetic underpinnings of the later aspects of progression toward addiction that are likely to be memory related.

\section{THE SCOPE OF CURRENT MOLECULAR GENETIC DATA FOR ADDICTIONS}

Linkage-based approaches that examine the way in which disease vulnerability and genomic markers move together through families have been used to study addictions to both legal and illegal addictive substances, with most work focused on alcohol and tobacco. ${ }^{22-34}$ Only a few of the results of these studies have converged convincingly, with the major linkage peak produced by a number of studies being poorly, if at all, supported by subsequent data (e.g., see ${ }^{22-26}$ ). Indeed, assemblies of current results from at least some linkage-based genomes can produce results that cover the majority of the genome with data that derive from at least some reported linkage peak in at least one study (C Johnson, GR Uhl, unpublished observations, 2005). Use of linkage-based methods has also produced modestly convergent results when applied by different laboratories to different samples in a number of other complex disorders. Nevertheless, compared with data from association genome scans (see below), these data produce compelling convergences that support a reasonably modest degree of genetic heterogeneity for much of human addiction vulnerability.

Association genome scanning can also elucidate chro- mosomal regions and genes that contain allelic variants that predispose to complex disorders, including substance abuse. This approach examines the ways in which disease vulnerability and genomic markers move together through populations and as such does not require family member participation. This approach gains power as the number of genomic markers that can be applied to the studies increases (FIG. 1). Results from association approaches identify smaller chromosomal regions than linkage-based approaches, allowing focus on specific genes. We thus focus the subsequent discussion on the results of association approaches and compare them with data from linkage studies from other laboratories.

Our addiction vulnerability association genome scans compared allelic frequencies beginning with 1494 and progressing to 11,522 , then 126,000 , and, more recently, 520,000 single nucleotide polymorphisms (SNPs) in each of two growing samples of unrelated polysubstance abusers and controls who reported no substantial lifetime use of any addictive substance. ${ }^{34,35}$ Initial data identified 41 of 1494 SNPs and 38 of 11,522 SNPs that displayed nominally "reproducibly positive" allele frequency differences between abuser and controls in both European- and AfricanAmerican samples using increasingly stringent criteria. These "reproducibly positive" markers (Table 1) clustered much closer to positive markers from linkage studies of addictions than anticipated by chance. ${ }^{33-35}$ However, this total of 13,015 SNPs provided information about possible associations with addiction for only a modest number of the blocks of restricted haplotype diversity found in these subjects' genomes and thus only modest power (FIG. 1). We have more recently validated association genome scanning with "100k" and "500k" (Centurion and Mendel Affymetrix) microarrays and used this approach to generate more than 3.2 billion person/genotype equivalents from European- and African-American polysubstance abusers versus controls (GR Uhl, QR Liu et al., manuscript in preparation). These polysubstance abusers report dependence on at least one illegal substance, while control individuals report no significant lifetime use of any addictive substance. We were able to compare the results of this work with data from smaller samples of alcohol-dependent versus control and methamphetamine dependent versus control individuals studied with 100k arrays ${ }^{36}$ (Drgon et al., submitted for publication).

We analyzed data from more than 639,000 SNPs assigned to chromosomes 1-22 using a pooled approach that generated SEM for the differences between the four replicate studies of each DNA pool of \pm 0.027 and SEM for pool-to-pool differences for individuals of the same phenotype and ethnicity of \pm 0.03 . These data thus provide good power to detect modest to moderate differences in allele frequencies between addict and control samples (FIG. 2), although power drops as the effect size is reduced.

Assessment of $>600,000$ repeated tests on the same 


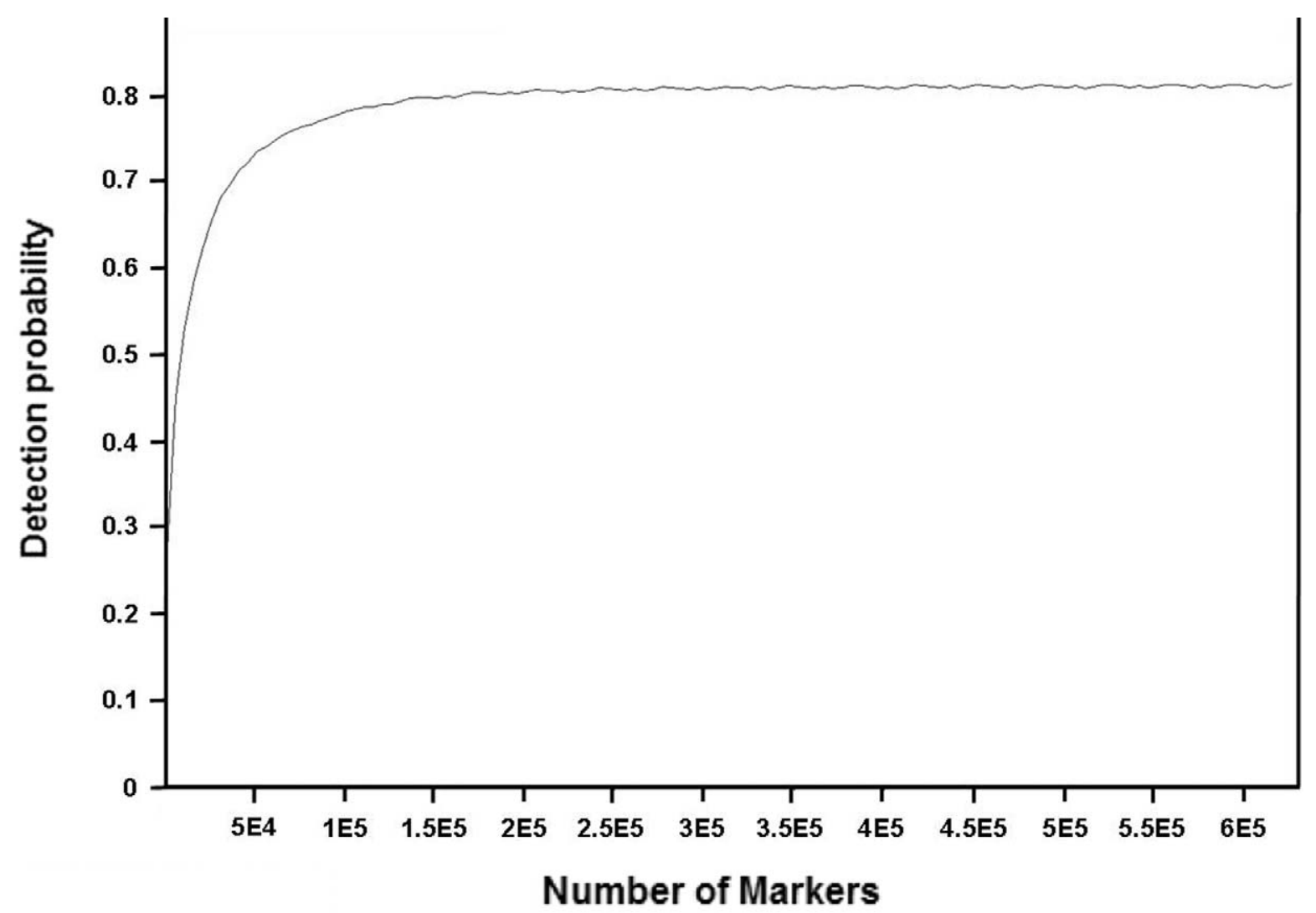

FIG. 1. Power for association genome scanning with increasing marker density. Modeling based on detection of a locus that increases risk to a first degree relative by 1.75 -fold. Note that recent studies support approximately total eight-fold risk to first-degree relatives from all heritable influences (reviewed in ref ${ }^{1}$ ). Power of association genome scanning (curved lines, with power levels associated with each line) from the "gene detective program" for modeling power of association genome scanning (D Naiman, GR Uhl, manuscript in preparation).

sample provides a problem of multiple comparisons. To begin to control for this multiple comparison problem, we first focused on "reproducibly positive" SNPs that displayed nominally significant differences between addicts and controls in each of two samples, a EuropeanAmerican sample and an African-American sample. We then focused on the clustered reproducibly positive SNPs, small chromosomal sites in which at least three of these reproducibly positive SNPs lay near each other. Finally, we identified areas in which these clustered, reproducibly positive SNPs lay in identifiable genes that were also identified by positive SNPs from both of two additional 100,000 SNP genome scans of alcohol-dependent versus control and from methamphetamine-dependent versus control samples. Very rarely are such genes found in simulation studies that ask how many times SNPs that are randomly selected from these datasets display the properties displayed by the SNPs that are identified in these studies. When the data are corrected using false discovery rate statistical approaches, genes identified in this way retain high levels of statistical significance as well (GR Uhl, QR Liu et al., manuscript in preparation).
While our analyses of many of these genes are incomplete, the identification of such genes through comparisons of several addict/control samples from different ethnic groups offers evidence that evolutionarily old allelic variants that are present in several current populations represent substantial amounts of the variance that underlie human addiction vulnerability. The gene classes that are identified in this way are also striking: these results point to genes related to cell adhesion, transcriptional regulation, and enzymes as the most represented class of genes that harbor such addiction-associated variants. The number of "cell adhesion"-related genes, in particular, is especially disproportionate to their representation in the genome. Such observations also come from the 10k data displayed in Table $1 .^{35}$ Neurexin 3 is a cell adhesion gene $^{37}$ and the AIP1 (atrophin interacting protein 1) gene, which is also known as S-SCAM (subcellular scaffolding cell adhesion molecule), plays a role in helping to anchor and localize the neurexin 3 ligand, neuroligin. ${ }^{38}$ Thus, even this modest-density SNP genome scan has identified two of the gene products that participate in one of the major cell adhesion events that helps to specify excitatory versus inhibitory synapse formation and/or 
TABLE 1. Association Genome Scanning Data from Two Unique Populations of Polysubstance Abusers

\begin{tabular}{|c|c|c|c|c|c|c|c|}
\hline Ref SNPs & $\mathrm{Ch}$ & $\mathrm{kbp}$ & Candidate Gene & Ref SNPs & $\mathrm{Ch}$ & $\mathrm{kbp}$ & Candidate Gene \\
\hline rs4492636 & 1 & 94,541 & $\mathrm{n} / \mathrm{a}$ & rs1362985 & 7 & 133,447 & SLC35B4 (5' flank) \\
\hline rs 1553695 & 1 & 160,359 & RGS5 (in gene) & rs721905 & 9 & 8,149 & $\mathrm{n} / \mathrm{a}$ \\
\hline rs664574 & 1 & 216,095 & $\mathrm{n} / \mathrm{a}$ & A1509247 & 10 & 8,275 & $\begin{array}{l}\text { GATA binding } \\
\text { protein } 3^{*}\end{array}$ \\
\hline rs1330695 & 1 & 240,633 & $\mathrm{n} / \mathrm{a}$ & rs958425 & 10 & 23,515 & $\begin{array}{l}\text { Chr10 ORF115 (in } \\
\text { gene) }\end{array}$ \\
\hline rs934993 & 2 & 4,450 & TSSC1 (3' flank) & rs2891427 & 10 & 54,158 & $\mathrm{n} / \mathrm{a}$ \\
\hline rs 1435572 & 2 & 179,145 & PDE11A (5' flank) & rs 1792525 & 11 & 56,492 & OR5AK2/3 5' flank \\
\hline rs1373340 & 3 & 66,835 & $\mathrm{n} / \mathrm{a}$ & rs870333 & 11 & 78,536 & $\begin{array}{l}\text { LOC440057 similar to } \\
\text { gamma-heregulin } \\
\text { (in gene) }\end{array}$ \\
\hline rs2215267 & 4 & 17,470 & KIAA1276 (in gene) & rs915286 & 13 & 38,493 & $\mathrm{n} / \mathrm{a}$ \\
\hline rs1395475 & 4 & 102,573 & PPP3CA (in gene) & rs1414291 & 13 & 89,236 & LOC144776 (3' flank) \\
\hline rs 1445002 & 5 & 40,365 & $\mathrm{n} / \mathrm{a}$ & rs1959959 & 14 & 60,583 & SYT14L (3' flank) \\
\hline rs329124 & 5 & 133,941 & PHF15 (in gene) & rs760288 & 14 & 78,296 & Neurexin3 (in gene) \\
\hline rs723677 & 5 & 143,190 & $\mathrm{HB} 1$ ( $5^{\prime}$ to gene) & rs 735612 & 15 & 31,792 & RYR3 (in gene) \\
\hline rs1039322 & 5 & 157,166 & LSM11 (3' flank) & rs2019877 & 17 & 69,271 & FLJ40319 (in gene) \\
\hline rs 201250 & 6 & 10,121 & OFCC1 $\left(5^{\prime}\right.$ end $)$ & rs1355828 & 18 & 35,567 & LOC388474 (in gene) \\
\hline rs4409192 & 6 & 144,903 & Utrophin* & rs1942578 & 18 & 73,319 & $\mathrm{n} / \mathrm{a}$ \\
\hline rs1380381 & 7 & 16,557 & TM4SF13 (in gene) & rs471216 & 22 & 25,935 & $\mathrm{n} / \mathrm{a}$ \\
\hline rs1917288 & 7 & 51,319 & $\begin{array}{l}\text { Cordon-bleu hom ( } 5^{\prime} \\
\text { flank) }\end{array}$ & rs 1883387 & 22 & 33,531 & LOC402059 (in gene) \\
\hline rs1406159 & 7 & $\mathbf{7 8 , 4 8 1}$ & $\begin{array}{l}\text { Atrophin interacting } \\
\text { protein } 1 \text { (in gene) }\end{array}$ & rs724534 & $\mathrm{X}$ & 115,412 & $\mathrm{n} / \mathrm{a}$ \\
\hline rs953023 & 7 & 112,701 & PP1R3A (3' flank) & rs726396 & $\mathrm{X}$ & 148,841 & $\mathrm{n} / \mathrm{a}$ \\
\hline
\end{tabular}

* Association genome scanning data (from Liu and coworkers). ${ }^{36}$ Two of the genes identified in this work that relate to cell adhesion as discussed in the text, neurexin 3 and atrophin interacting protein 1/S-SCAM gene, are highlighted.

Ref SNPs = reference SNPs; $\mathrm{Ch}=$ chromosome; $\mathrm{kbp}=$ kilobase pairs.

maintenance. ${ }^{37}$ These genes are thus good candidates to contribute to the differences in neuronal connectivities through their differential expression in the developing brain and/or the in adult brain. One of the genes that was identified based on the initial 1500 SNP association genome scan is also a cell adhesion molecule, $\mathrm{NrCAM}$, the neuroglian-related cell adhesion molecule. While our analyses of many of the cell adhesion molecule genes from more recent genome scanning work is incomplete, work on $\mathrm{NrCAM}$ illustrates a number of these points.

\section{NRCAM: A POSITIONALLY CLONED CELL ADHESION MOLECUULE GENE WHOSE VARIANTS MAY CONTRIBUTE TO ADDICTIVE, MNEMONIC, AND REGIONAL BRAIN VOLUME}

We identified $\mathrm{NrCAM}$ as an addiction vulnerability gene based on several lines of evidence. ${ }^{38}$ First, we began fine mapping studies of the region of chromosome 7 that contained one of the more strongly associated SNPs from our initial study of 1500 microarray data in a region that also contained the strongest linkage to alcohol dependence in the Collaborative Study on the Genetics of Alcoholism (wave I). ${ }^{23,34}$ After typing many markers in this region, we identified 5' NrCAM haplotypes that are associated with substance abuse vulnerabilities in each of four samples of abusers versus controls, with the same "phase" of association in abuser/control comparisons from European-American, African-American, and Asian samples. ${ }^{38}$ Independently, we had also isolated $\mathrm{NrCAM}$ as a gene whose expression levels were regulated by morphine based on a subtracted hybridization/ differential display assay, data that also characterize $\mathrm{Nr}$ $C A M$ as a drug-regulated gene. ${ }^{38}$ Third, we sought to understand the cellular and regional localization of $\mathrm{Nr}$ $\mathrm{CAM}$ and identified its expression in neurons linked to reward in the ventral midbrain and in neurons linked to mnemonic systems in hippocampus and cerebral cortex. ${ }^{36}$ Fourth, we identified evidence for differential expression of the addiction-associated $\mathrm{NrCAM}$ haplotypes in postmortem brain samples. ${ }^{38}$ Since heterozygous individuals can have one of the addiction-associated $\mathrm{Nr}$ CAM haplotypes and one other haloptype, we were able to compare the levels of expression of the mRNAs made from each of these two haplotypes using an allele-specific expression assay and found lower expression of the NrCAM haplotype that was less abundant in substance abusers than in control individuals. We were thus able to model these human differences in heterozygous NrCAM knockout mice, which show almost exactly half of the NrCAM expression displayed by their wild-type littermates. In these heterozygous knockouts, we could test a 


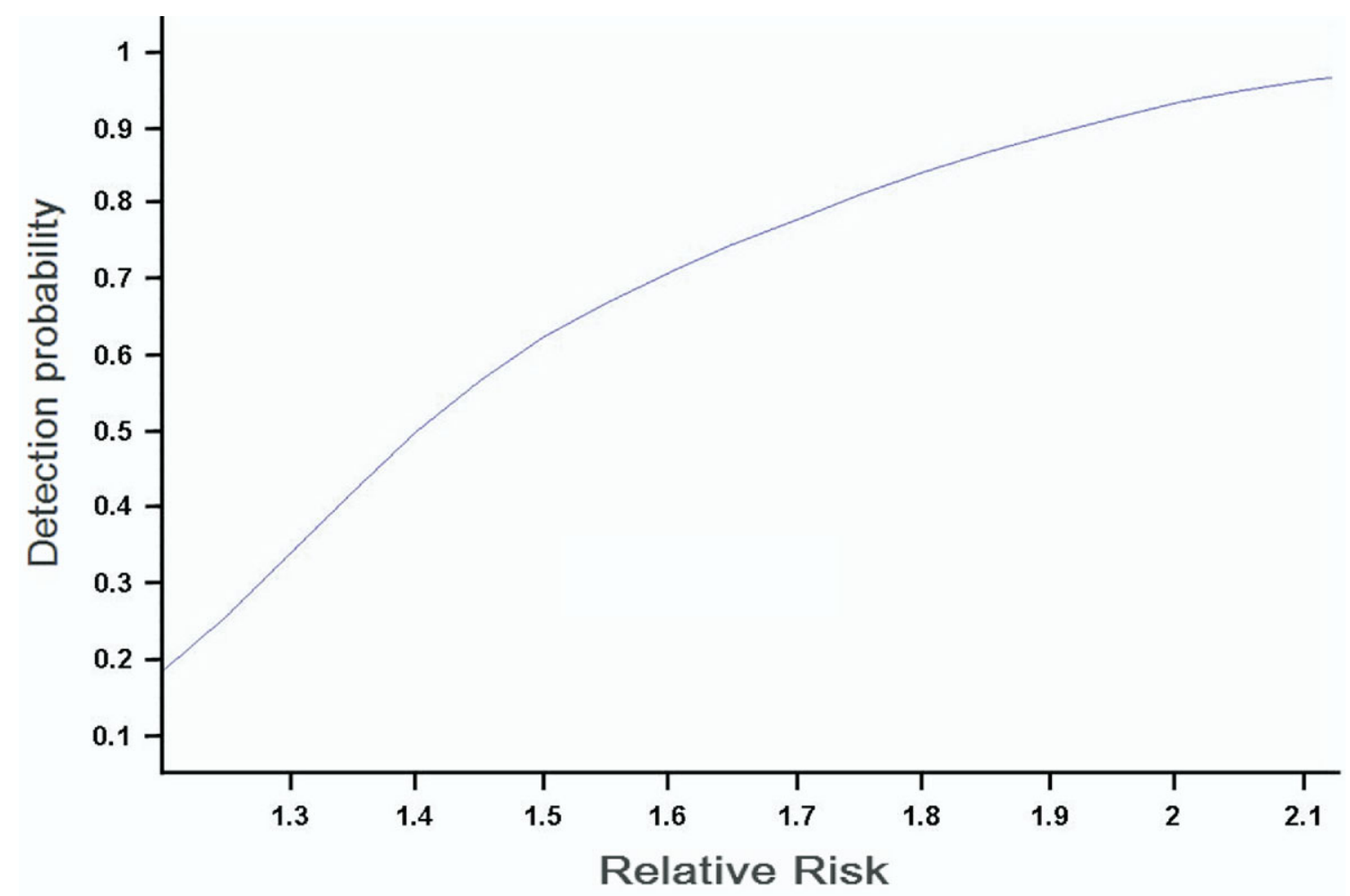

FIG. 2. Power for association genome scanning to detect loci with increasing relative risk to a first-degree relative of an affected individual. Modeling based on 630,000 genome-wide markers. Power of association genome scanning (curved lines, with power levels associated with each line) from the "gene detective program" for modeling power of association genome scanning (D Naiman, GR Uhl, manuscript in preparation).

combination of drug reward and drug memory in a "conditioned place preference" test that assesses the increased time that a mouse spends in a previously drug-paired environment. Remarkably, there was a dramatically lower preference for the places where NrCAM heterozygous knockouts received morphine and for the place where other knockouts received cocaine or an amphetamine. ${ }^{38}$ Thus, these mouse data fit well with the human data.

With these NrCAM haplotypes and mouse models in hand, we can ask about the possibility that these gene variants could exert plieotrophic effects on other brain functions and structures. When NrCAM knockout mouse brains are examined grossly, there is little evidence for overall changes in brain size or structure. When we focused on the dopaminergic midbrain neurons that are likely candidates for involvement in NrCAM effects on reward mechanisms, we identified no significant changes in the number of these cells as determined by tyrosine hydroxylase immunohistochemistry (J Drgonovna, F Scott Hall, GR Uhl, unpublished observations, 2004). However, when mice are bred that combine reduced $\mathrm{NrCAM}$ expression with reduced expression of another cell adhesion molecule, L1, brains are substantially smaller. ${ }^{39}$ Thus, in the context of other genetic variations, $\mathrm{NrCAM}$ haplotypes are candidates to contribute to individual differences in brain volumes in humans. We can hypothesize that changes in gray matter volumes are good candidates to contribute to these changes in brain sizes.

NrCAM variations are also strong candidates to contribute to individual differences in mnemonic and cognitive processes that are linked genetically. While $\mathrm{Nr}$ CAM knockouts perform normally in some tests of memory and performance, they display significant deficits in Lashley maze performance. This maze requires a mouse to remember the direction it previously turned, so that he can turn in the opposite direction at the next choice point (M Grumet et al., unpublished observations, 2004). Further, recent reports document association of NrCAM 5' haplotypes with one of the prototypical disorders of mnemonic and cognitive systems, autism. These associations have been made in one sample with markers for the same haplotype that are independent of the ones that we have employed in our studies and in another study examining autism subjects versus control subjects using the same markers employed in our studies (see ${ }^{40}$; T Sakurai et al., personal communication). Thus, there is relatively strong support for the idea that these NrCAM variants can exert plieotropic effects on addiction relevant and mnemonic/cognitive systems in humans and in animal models. 


\section{CAVEATS AND LIMITATIONS}

The work reviewed here is at the edge of a burgeoning wave of molecular genetic studies of complex disorders. It thus needs to be understood with many of the same sorts of cautions that are required for most studies in this exciting and rapidly changing area. In disorders in which single gene variants contribute relatively large amounts of the attributable risk for a disease in the general population, such as those identified in recent observations concerning adult macular degeneration, ${ }^{41}$ identification of such variants can be made in single samples with relatively high degrees of statistical confidence. Replication can follow in multiple samples, even those of uneven quality. However, few studies in complex genetic disorders, including those reviewed here, identified such "oligogene" influences. Instead, the magnitudes of association signals and the reproducible components of linkage signals that have been identified to date are more consistent with polygenic inheritance. Such signals, in the context of testing that necessarily encompasses haplotypes at hundreds of thousands of genomic loci, are setups for production of false-positive data. For this reason, this review focuses only on genes that display nominally statistically positive association signals in studies of several populations. Simulations provide one way to account for the multiple testing. However, to date there is no single convincing statistical means of analyzing such data that will yield consistent approval from all statisticians. (See reviews by Olson ${ }^{42}$ and Almudevar et al. ${ }^{43}$ in this issue for discussions on statistical analyses in highdimensional data.) In this context, any reader of this sort of data should stay alert to possible reinterpretations of nominally positive results in light of advances in use of statistical methods in genetics. Integrating false discovery rate statistics into these studies provides one of the emerging trends in this area. ${ }^{44}$

However, in this context, false-negative results also become much more likely. Any significant assay noise or random variation in the samples used is quite likely to provide at least one failure to achieve significance if a modest effect is sought in four samples, as noted above. If the four samples provide $\sim 0.9-0.6$ power, for example, the joint probability of missing a true positive result in at least one of four samples is $70 \%$. The molecular biologic approaches to genotyping hundreds of thousands of SNPs have proceeded faster than the ability of statistical genetics to provide generally agreed solutions to the problems raised by the many multiple comparisons that are part of these large association studies.

Genetic confidentiality and assurances that genotypebased information will not be used to hinder employment or insurability represent true potential barriers to use of the sort of genotype information that comes from complex genetic studies. While legislative initiatives are un- derway to address these issues (http://slashdot.org/article. $\mathrm{pl}$ ?sid $=03 / 10 / 15 / 222234$ ), they remain troubling at the current time. This is especially true as more and more individuals' genetic profiles are maintained in central databases derived from crime scene samples (http://www. fbi.gov/hq/lab/codis/national.htm; 130,877 forensic profiles and 2941,206 convicted offender profiles listed in February 2006), military inductees (http://www.afip.org/ Departments/oafme/dna/), etc.

\section{POTENTIAL IMPACT}

We have recently described the large financial impact of such complex genetic contributions to addiction in the United States. ${ }^{45}$ Improved understanding of addiction that comes from molecular genetic studies could well play a role in better designing strategies to treat addictions and to improve matching of addicted individuals with the treatments likely to work best for them. However, addiction prevention is even more desirable. Applying information about the status of the common allelic variants that are being identified in association genome scanning studies should aid physicians in designing treatment strategies when considering use of drugs with significant abuse liability in treating potentially more vulnerable or less vulnerable individuals. Such efforts could reduce the growth of the problem posed by abuse of prescription drugs and should even become a more and more necessary component of clinical trials of promising new therapeutics with potential abuse liability within the near future. Further, haplotypes in NrCAM, neurexin 3, and at least 20 additional "cell adhesion"-related genes that we are now identifying provide useful tools for thinking about stratifying individuals for imaging studies, especially when the focus is on cerebral cortical and hippocampal regions known to display substantial heritability. Markers in these genes should also be considered in stratifying individuals for mnemonic testing, including the testing of memory-enhancing drugs.

Acknowledgments: I am grateful for the help with personal studies cited here from Qing-Rong Liu, Daniel Naiman, Judith Hess, Bruce O'Hara, Antonio Persico, Donna Walther, Fely Carillo, Brenda Campbell, Linda Kahler, Fred Snyder, Carlo Contoreggi, Larry Rodriguez, Robert Grow, David Gorelick, Zhicheng Lin, Andrew Shapiro, and Leslie Cope and financial support from the National Institutes of Health-Intramural Research Program (National Institute on Drug Abuse).

\section{REFERENCES}

1. Uhl GR. Molecular genetic underpinnings of human substance abuse vulnerability: likely contributions to understanding addiction as a mnemonic process. Neuropharmacology 47 [Suppl 1]:140147, 2004.

2. Berke JD, Hyman SE. Addiction, dopamine, and the molecular mechanisms of memory. Neuron 25:515-532, 2000.

3. Nestler EJ. Common molecular and cellular substrates of addiction and memory. Neurobiol Learn Mem 78:637-647, 2002. 
4. Smith MY, Woody G. Nonmedical use and abuse of scheduled medications prescribed for pain, pain-related symptoms, and psychiatric disorders: patterns, user characteristics, and management options. Curr Psychiatry Rep 7:337-343, 2005.

5. Uhl GR, Elmer G, Pickens R. Genetic influences in drug abuse. In: Psychopharmacology: the fourth generation. (Bloom FE, Kupfer DJ, eds), pp 1793-1806. New York: Raven Press, 1995.

6. Uhl GR, Liu QR, Naiman D. Substance abuse vulnerability loci: converging genome scanning data. Trends Genet 18:420-425, 2002 .

7. Uhl GR. Molecular genetics of substance abuse vulnerability: a current approach. Neuropsychopharmacology 20:3-9, 1999.

8. Kendler KS, Karkowski LM, Corey LA, Prescott CA, Neale MC Genetic and environmental risk factors in the aetiology of illicit drug initiation and subsequent misuse in women. Br J Psychiatry 175:351-356, 1999.

9. Kendler KS, Prescott CA. Cocaine use, abuse and dependence in a population-based sample of female twins. Br J Psychiatry 173: 345-350, 1999.

10. Kendler KS, Prescott CA, Neale MC, Pedersen NL. Temperance board registration for alcohol abuse in a national sample of Swedish male twins, born 1902 to 1949. Arch Gen Psychiatry 54:178184, 1997.

11. Kendler KS, Thornton LM, Pedersen NL. Tobacco consumption in Swedish twins reared apart and reared together. Arch Gen Psychiatry 57:886-892, 2000.

12. Pickens RW, Svikis DS, McGue M, Lykken DT, Heston LL, Clayton PJ. Heterogeneity in the inheritance of alcoholism: a study of male and female twins. Arch Gen Psychiatry 48:19-28, 1991.

13. True WR, Heath AC, Scherrer JF, Xian H, Lin N, Eisen SA et al. Interrelationship of genetic and environmental influences on conduct disorder and alcohol and marijuana dependence symptoms. Am J Med Genet 88:391-397, 1999.

14. True WR, Xian H, Scherrer JF, Madden PA, Bucholz KK, Heath $\mathrm{AC}$ et al. Common genetic vulnerability for nicotine and alcohol dependence in men. Arch Gen Psychiatry 56:655-661, 1999.

15. Tsuang MT, Lyons MJ, Eisen SA, Goldberg J, True W, Lin N et al. Genetic influences on DSM-III-R drug abuse and dependence: a study of 3,372 twin pairs. Am J Med Genet 67:473-477, 1996.

16. Tsuang MT, Lyons MJ, Harley RM, Xian H, Eisen S, Goldberg J et al. Genetic and environmental influences on transitions in drug use. Behav Genet 29:473-479, 1997.

17. Tsuang MT, Lyons M J, Meyer JM, Doyle T, Eisen SA, Goldberg $\mathrm{J}$ et al. Co-occurrence of abuse of different drugs in men: the role of drug-specific and shared vulnerabilities. Arch Gen Psychiatry 55:967-972, 1998

18. Wright M, De Geus E, Ando J, Luciano M, Posthuma D, Ono Y, et al. Genetics of cognition: outline of a collaborative twin study. Twin Res 4:48-56, 2001.

19. Geschwind DH, Miller BL, DeCarli C, Carmelli D. Heritability of lobar brain volumes in twins supports genetic models of cerebral laterality and handedness. Proc Natl Acad Sci USA 99:3176-3181, 2002.

20. Sullivan EV, Pfefferbaum A, Swan GE, Carmelli D. Heritability of hippocampal size in elderly twin men: equivalent influence from genes and environment. Hippocampus 11:754-762, 2001.

21. Posthuma D, Baare WF, Hulshoff Pol HE, Kahn RS, Boomsma DI, De Geus EJ. Genetic correlations between brain volumes and the WAIS-III dimensions of verbal comprehension, working memory, perceptual organization, and processing speed. Twin Res 6:131139, 2003.

22. Long JC, Knowler WC, Hanson RL, Robin RW, Urbanek M, Moore E, et al. Evidence for genetic linkage to alcohol dependence on chromosomes 4 and 11 from an autosome-wide scan in an American Indian population. Am J Med Genet 81:216-221, 1998.

23. Reich T, Edenberg HJ, Goate A, Williams JT, Rice JP, Van Eerdewegh $\mathrm{P}$ et al. Genome-wide search for genes affecting the risk for alcohol dependence. Am J Med Genet 81:207-215, 1998.

24. Stallings MC, Corley RP, Hewitt JK, Krauter KS, Lessem JM, Mikulich SK et al. A genome-wide search for QTLs influencing substance dependence vulnerabity in adolescence. Drug Alcohol Depend 70:295-307, 2003.
25. Straub RE, Sullivan PF, Ma Y, Myakishev MV, Harris-Kerr C, Wormley B et al. Susceptibility genes for nicotine dependence: a genome scan and followup in an independent sample suggest that regions on chromosomes 2, 4, 10, 16, 17 and 18 merit further study. Mol Psychiatry 4:129-144, 1999.

26. Foroud T, Edenberg HJ, Goate A, Rice J, Flury L, Koller DL et al. Alcoholism susceptibility loci: confirmation studies in a replicate sample and further mapping. Alcohol Clin Exp Res 24:933-945, 2000.

27. Gelernter J, Panhuysen C, Weiss R, Brady K, Hesselbrock V, Rounsaville $\mathrm{B}$ et al. Genomewide linkage scan for cocaine dependence and related traits: significant linkages for a cocaine-related trait and cocaine-induced paranoia. Am J Med Genet 136:45-52, 2005.

28. Gelernter J, Liu X, Hesselbrock V, Page GP, Goddard A, Zhang H. Results of a genomewide linkage scan: support for chromosomes 9 and 11 loci increasing risk for cigarette smoking. Am J Med Genet 128:94-101, 2004.

29. Wang D, Ma JZ, Li MD. Mapping and verification of susceptibility loci for smoking quantity using permutation linkage analysis. Pharmacogenomics J 5:166-172, 2005.

30. Ma JZ, Zhang D, Dupont RT, Dockter M, Elston RC, Li MD. Mapping susceptibility loci for alcohol consumption using number of grams of alcohol consumed per day as a phenotype measure. BMC Genet 31 [Suppl 1]:S104, 2003.

31. Li MD, Ma JZ, Cheng R, Dupont RT, Williams NJ, Crews KM,. et al. Framingham Heart Study: a genome-wide scan to identify loci for smoking rate in the Framingham Heart Study population. BMC Genet 31 [Suppl 1]:S103, 2003.

32. Bergen AW, Yang XR, Bai Y, Beerman MB, Goldstein AM, Goldin LR. Framingham Heart Study: genomic regions linked to alcohol consumption in the Framingham Heart Study. BMC Genet 31 [Suppl 1]:S101, 2003.

33. Uhl GR. Molecular genetics of substance abuse vulnerability: remarkable recent convergence of genome scan results. Ann NY Acad Sci 1025:1-13, 2004.

34. Uhl GR, Liu QR, Walther D, Hess J, Naiman D. Polysubstance abuse-vulnerability genes: genome scans for association, using 1,004 subjects and 1,494 single-nucleotide polymorphisms. Am J Hum Genet 69:1290-1300, 2001.

35. Liu QR, Drgon T, Walther D, Johnson C, Poleskaya O, Hess J et al. Pooled association genome scanning: validation and use to identify addiction vulnerability loci in two samples. Proc Natl Acad Sci USA 102:11864-11869, 2005.

36. Johnson C, Drgon T, Liu Q-R, Walther D, Edenberg H, Rice J, Foroud T, Uhl GR. Pooled association genome scanning for alcohol dependence using 104,268 SNPS: validation and use to identify alcoholism vulnerability loci in unrelated individuals from the Collaborative Study on the Genetics of Alcoholism. American J Med Genetics (Part B) (in press).

37. Dean C, Dresbach T. Neuroligins and neurexins: linking cell adhesion, synapse formation and cognitive function. Trends Neurosci 29:21-29, 2006.

38. Ishiguro H, Liu QR, Gong JP, Hall FS, Ujike H, Morales $\mathrm{M}$ et al. NrCAM in addiction vulnerability: positional cloning, drug-regulation, haplotype-specific expression and altered drug reward in knockout mice. Neuropsychopharmacology 31:572-584, 2006.

39. Sakurai T, Lustig M, Babiarz J, Furley AJ, Tait S, Brophy PJ et al. Overlapping functions of the cell adhesion molecules Nr-CAM and L1 in cerebellar granule cell development. J Cell Biol 154:12591273, 2001

40. Bonora E, Lamb JA, Barnby G, Sykes N, Moberly T, Beyer KS et al. Mutation screening and association analysis of six candidate genes for autism on chromosome 7q. Eur J Hum Genet 13:198207, 2005

41. Edwards AO, Ritter R III, Abel KJ, Manning A, Panhuysen C, Farrer LA. Complement factor $\mathrm{H}$ polymorphism and age-related macular degeneration. Science 308:421-424, 2005.

42. Olson NE. The microarray data analysis process: from raw data to biological significance. NeuroRx 2006.

43. Almudevar et al. NeuroRx 2006.

44. Storey JD, Tibshirani R. Statistical significance for genomewide studies. Proc Natl Acad Sci USA 100:9440-9445, 2003.

45. Uhl GR, Grow RW. The burden of complex genetics in brain disorders. Arch Gen Psychiatry 61:223-239, 2004. 